\title{
Classic congenital adrenal hyperplasia due to 21-hydroxylase deficiency
}

INSERM

\section{Source}

INSERM. (1999). Orphanet: an online rare disease and orphan drug data base. Classic congenital adrenal hyperplasia due to 21-hydroxylase deficiency. ORPHA:90794

Classic cong enital adrenal hyperplasia due to 21-hydroxylase deficiency (classic 21-OHD $\mathrm{CAH}$ ) is the most common form of congenital adrenal hyperplasia (CAH; see this term), characterized by simple virilizing or salt wasting forms that can manifest with genital ambiguity in females and with adrenal insufficiency (in both sexes), and that presents with dehydration, hypoglycemia in the neonatal period (that can be lethal if untreated), and hyperandrogenia. 